\title{
Anatomic variations of the nasal cavity and paranasal sinus and their correlation with chronic rhinosinusitis using Harvard staging system
}

\begin{abstract}
Objective: To determine the prevalence of anatomic variations of the nasal cavity and paranasal sinus of patients with Chronic Rhinosinusitis (CRS) and correlate with the extent of CRS using the Harvard Staging System.

Methods:

Design: Correlational Study

Setting: Tertiary Government Hospital

Participants: All adult ( $>18$ years old) patients clinically diagnosed to have Chronic Rhinosinusitis who undergone Paranasal Sinus CT scan from January 2014 to April 2017.

Results: There were 60 patients with CRS included in this study with males predominantly at $71.7 \%(\mathrm{n}=43)$ and females at $28.3 \%(\mathrm{n}=17) .28 .3 \%(\mathrm{n}=17)$ of cases were noted in $31-40$ years old age group. The most common anatomical variants were Agger Nasi cells $78.3 \%$ $(\mathrm{n}=47)$, Haller cells $41.6 \%(\mathrm{n}=25)$, Septal Deviation 20.0\% $(\mathrm{n}=12)$, Concha Bullosa 11.7 $(\mathrm{n}=7)$. A high prevalence of anatomic variations was noted in stage III and IV disease except for Haller cells $24.0 \%(n=6)$ and Concha Bullosa $33.3 \%(n=2)$ which were noted in stage I. A significantly high frequency of anatomic variations was noted among patients with CRS in this study at $92.0 \%(\mathrm{n}=55)$.

Conclusion: This study revealed that most of the patients with CRS are male and those who belong in the 31-40 year old age group. The most common anatomical variants found were Agger Nasi cells, Haller cells, Septal Deviation and Concha Bullosa. A strong correlation was established between Agger Nasi cells, Septal Deviation, Everted Uncinate Process and Paradoxical Middle Turbinates with the extent of Chronic Rhinosinusitis using Harvard Staging System.
\end{abstract}

Keywords: chronic rhinosinuistis, anatomic variations, harvard staging system, turbinates, haller cells
Volume 10 Issue 4 - 2018

\author{
Wenrol Espinosa, Rolen Genito, Rachel Zita \\ Ramos \\ Corazon Locsin Montelibano Memorial Regional Hospital, \\ Philippines
}

\begin{abstract}
Correspondence: Wenrol Espinosa, Corazon Locsin Montelibano Memorial Regional Hospital, Cor. BurgosLacson St., Bacolod City, Negros Occidental, Philippines, Tel +639173032009, Email wespinosa686@gmail.com
\end{abstract}

Received: December 20, 2017 | Published: July 06, 2018

\section{Introduction}

Chronic Rhinosinusitis (CRS) is an inflammation of the nasal cavity and paranasal sinuses that lasts for at least 12 weeks. ${ }^{1}$ It is a consequence of infectious, viral, bacterial, or fungal processes. This may also be associated with allergy, nasal polyposis and mucosal vasomotor dysfunction.

Computerized Tomography (CT) scan allows for the analysis of anatomy of the nasal cavity and paranasal sinuses and its drainage. Various staging systems are available in assessing the severity of CRS based on CT scan imaging. Gliklich and Metson introduced the Harvard staging system in assessing the extent of CRS which involves the division of paranasal sinus and staged based on the opacity and mucosal thickness of each sinus. ${ }^{2} \mathrm{CT}$ imaging assesses both anatomic variations of the nasal cavity and paranasal sinus as well as extent of the disease.

A fundamental knowledge of the paranasal sinus anatomy is essential not only for the diagnosis of CRS but also for the preoperative planning prior to sinus surgery. ${ }^{3,4,5}$ However, orientation of the paranasal sinus still remains a challenge among otolaryngologists owing to the anatomic variations and diversity of prevalence among different ethnicity. ${ }^{6,7}$ Nouraei et al., ${ }^{8}$ divided anatomical variants into those with potential impact on sinus drainage and operative safety. Those with implications in sinus drainage are concha bullosa, paradoxical middle turbinate, congenital absence of middle turbinate, pneumatized or absent uncinate process, septal pneumatization and bulla ethmoidalis. ${ }^{8}$ Some authors claim that some of these anatomic variations can cause significant blockade of the osteomeatal complex. These variations consequently block the normal mucociliary clearance of sinuses and increase the risk for Chronic Rhinosinusitis. ${ }^{9}$ Bachert et al., ${ }^{1}$ further explains that anatomical variants which potentially blocks the free flow of mucociliary movement are usually associated with higher mucus viscosity and lower mucosal immunity against sinus infections. ${ }^{1}$ Baradaranfar et al., ${ }^{3}$ clearly describe the correlation of certain paranasal sinus anatomic variation attributes like size, location, and amount of mucosal contact to the development and severity of Chronic Rhinosinusitis among patients. ${ }^{3}$ This study aimed to determine the significant association of the anatomic variations of the paranasal sinus with the chronic rhinosinusitis using Harvard Staging System.

\section{Methods}

This is a retrospective study of all adults ( $>18$ years old) clinically diagnosed to have chronic rhinosinusitis (CRS) at a tertiary government hospital who underwent paranasal sinus CT scan from January 2014 to April 2017. 


\section{Sampling}

A cross sectional sampling of 60 patients was done in this 3-year study period. Patient data were retrieved at Patient Archiving and Compilation System (PACS) by the radiology department. The following inclusion and exclusion criteria were applied in the selection process

\section{Inclusion criteria}

i. All adult patients ( $>18$ years old) clinically diagnosed with CRS who have undergone paranasal sinus CT Scan from January 2014 to April 2017

\section{Exclusion criteria}

i. Foreign nationality and ethnicity

ii. Undergone prior nasal surgery

iii. Diagnosed with malignancy in the paranasal sinus

\section{Data procurement and analysis}

The identification of anatomic variants and staging was accomplished by the author and co-author. The following are the anatomic variations of the paranasal sinuses with implications in sinus drainage (Figure 1)

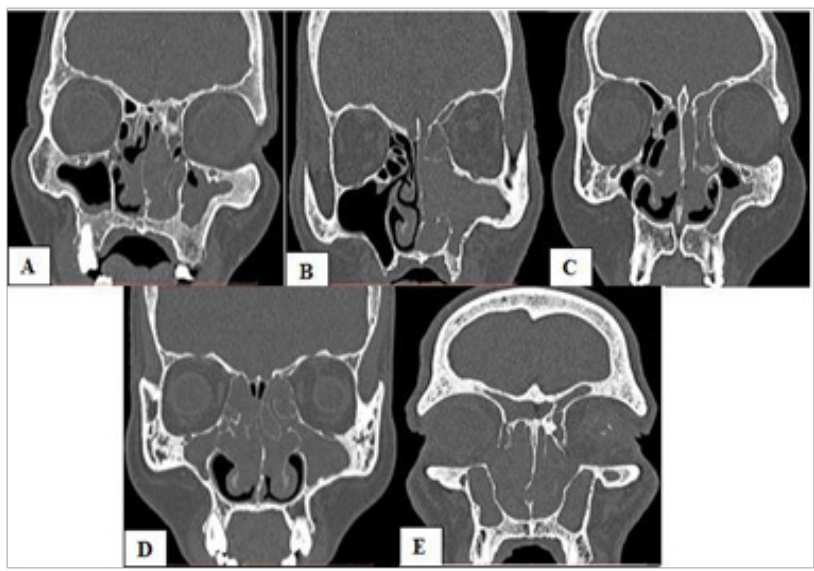

Figure I Anatomic variations on paranasal sinus CT scan;Agger nasi cell (A) Infraorbital (Haller) cell and Paradoxical middle turbinate (B) Concha bullosa (C) Everted uncinate process (D) Septal deviation (E). 28.3\%.

Agger Nasi cell-an anteriorly located extramural air cell not confined within the ethmoid bone. It is immediately anterior to the insertion of the middle turbinate forming the floor of the frontal recess.

Infraorbital (Haller) cell-an ethmoid air cell that extend along the medial floor of the orbit. Paradoxical middle turbinate-convexity of the middle turbinate is directed laterally. Concha bullosa-an aerated middle turbinate. Everted uncinate process-an abnormally projecting uncinate process medially toward middle turbinate.

Septal deviation-buckling in the nasal septum resulting in concavity on the other side of the septum and narrowing on the contralateral side.

Demographic data of patients and prevalence of anatomic variations were determined and a correlational study with extent of chronic rhinosinusitis using Harvard staging system was utilized to establish association.

\section{Results}

This study included 60 patients with males at $71.7 \%(\mathrm{n}=43)$ and females at $28.3 \%(n=17)$ (Figure 2). The age group with the most cases of CRS was the $31-40$ years old at $28.3 \%(n=17)$ (Figure 3 ). The frequency of anatomic variations is presented in Figure 4 showing Agger Nasi cells $78.3 \%(n=47)$ and Haller cells $41.6 \%(n=25)$ are found to be the predominant variants in the population. Table 1 demonstrates a positive correlation in frequency of anatomic variation and Harvard stage. A high frequency of anatomic variations was noted in stage III and IV disease except for Haller cells $24.0 \%(n=6)$ and concha bullosa $33.3 \%(\mathrm{n}=2)$ which were noted in early stage I disease. Patients with no anatomic variation represent only $8.0 \%(n=5)$ of the population. Thus, a significantly high frequency of patients with anatomic variation was noted in this study $92.0 \%(n=55)$.

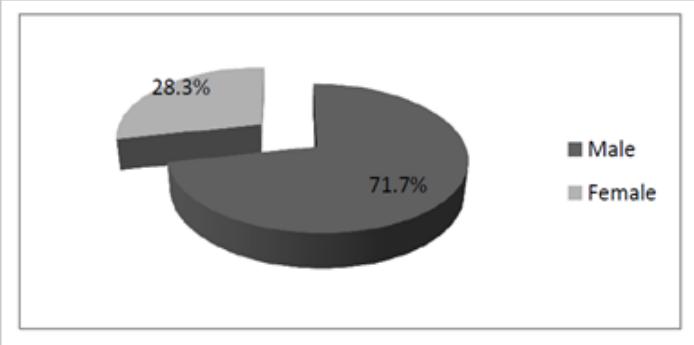

Figure 2 Gender distributions.

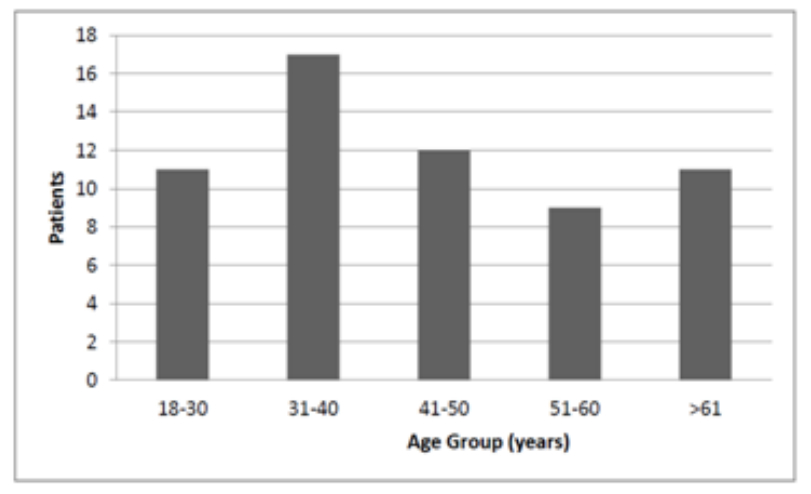

Figure 3 Age group distributions.

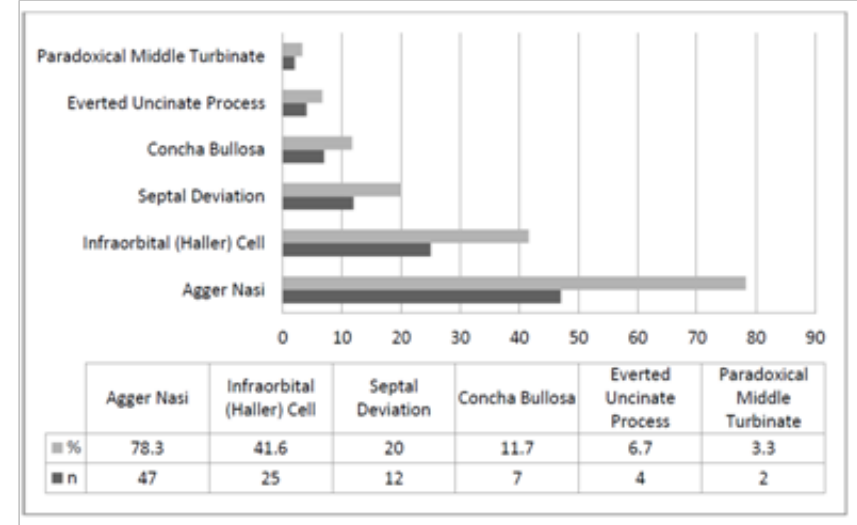

Figure 4 Prevalence of anatomic variations in all patients. 
Table I Frequency of anatomic variation in CRS according to Harvard stage

\begin{tabular}{|c|c|c|c|c|c|c|c|c|}
\hline \multicolumn{9}{|c|}{ Stage } \\
\hline & & I & II & & & III & & IV \\
\hline Anatomic & $\mathrm{n}$ & $\%$ & $\mathrm{n}$ & $\%$ & $\mathrm{n}$ & $\%$ & $\mathrm{n}$ & $\%$ \\
\hline \multicolumn{9}{|l|}{ Variation } \\
\hline Agger Nasi & 7 & 14.9 & 4 & 8.5 & II & 23.4 & 25 & 53.1 \\
\hline Infraorbital & 6 & 24 & 2 & 8 & 3 & 12 & 14 & 56 \\
\hline \multicolumn{9}{|l|}{ (Haller) Cell } \\
\hline Septal & I & 8.3 & 1 & 8.3 & 4 & 33.3 & 6 & 50 \\
\hline \multicolumn{9}{|l|}{ Deviation } \\
\hline Concha & 2 & 33.3 & I & 16.7 & 2 & 33.3 & I & 16.7 \\
\hline \multicolumn{9}{|l|}{ Bullosa } \\
\hline Everted & I & 25 & 0 & 0 & 2 & 50 & I & 25 \\
\hline \multicolumn{9}{|l|}{ Uncinate } \\
\hline \multicolumn{9}{|l|}{ Process } \\
\hline Paradoxical & I & 50 & 0 & 0 & I & 50 & 0 & 0 \\
\hline \multicolumn{9}{|l|}{ Middle } \\
\hline \multicolumn{9}{|l|}{ Turbinate } \\
\hline None & 0 & 0 & 1 & 20 & I & 20 & 3 & 60 \\
\hline
\end{tabular}

\section{Discussion}

In this study 60 patients were included and majority were males Most patients with CRS are between 31-40 years old at 28.3\% $(n=17)$ similar to the mean age of several studies. ${ }^{3,10,11}$

Numerous authors noted that certain anatomical variants have been associated with the pathophysiology of chronic rhinosinusitis particularly in sinus drainage..$^{12,3,6,7,13,9}$ In this study.

Agger Nasi cells 78.3\% $(n=47)$, Haller cells $41.6 \%(n=25)$, Septal Deviation 20.0\% ( $\mathrm{n}=12)$, Concha Bullosa 11.7\% ( $\mathrm{n}=-7)$, Everted Uncinate Process $6.7 \%(\mathrm{n}=4)$ and Paradoxical Middle Turbinate $3.3 \%(\mathrm{n}=2)$ were the anatomic variations noted. These findings were comparable to a local study by Santos et al and among Mediterranean and Caucasian population which showed Agger Nasi as the most prevalent anatomical variant followed by Septal Deviation and Concha Bullosa. $3,14,15,9$

In this study, an increase in the pattern prevalence of anatomical variants was found as Harvard stage increases, showing a positive correlation between the two variables, except for Haller cells and Concha Bullosa which can be attributed to previous studies that allergy and recurrent sinus infection might play a role. ${ }^{1,3}$ Pansinusitis (Stage IV) was noted in majority of the cases $53.3 \%(n=32)$ underlining the fact that most of our patients consulted at a later stage of the disease. Also noted in this study, 93.3\% ( $\mathrm{n}=56)$ among patients with CRS were noted to have anatomic variations emphasizing that anatomic variations are commonly found among patients with CRS.

\section{Conclusion}

In summary, this study revealed that most of the patients with CRS are males. Most of the patients belong in the 31-40 years age group. The most common anatomical variants were Agger Nasi cells, Haller cells, Septal Deviation and Concha Bullosa. A significantly high prevalence of anatomical variants was found among patients with CRS. Strong correlation was established between Agger Nasi cells, Septal Deviation, Everted Uncinate Process and Paradoxical Middle Turbinates with the extent of Chronic Rhinosinusitis using Harvard Staging System.

The sampling of this study is cross sectional by nature hence taking only a snapshot of a population in specific time frame. It is recommended that larger population studies will be conducted to augment the power of sample with an extended time period. An inherent limitation of a correlational study is the difficulty of establishing causal inference between variables. ${ }^{16-21}$

\section{Acknowledgments}

None.

\section{Conflict of interest}

There are no financial interests or any conflict of interest.

\section{References}

1. Bachert C, Pawankar R, Zhang L, et al. ICON: chronic rhinosinusitis. World Allergy Organ J. 2014;27;7(1):25. 
2. Gliklich R, Metson RA. Comparison of sinus computed tomography (CT) staging for outcomes research. AmJ Rhinol. 1994;8(6): 291-298.

3. Baradaranfar M, Labibi M. Anatomic Variations of Paranasal Sinuses in Patients with Chronic Sinusitis and their Correlation with CT Scan Imaging. Acta Medica Iranica. 2007;45(6):477-480.

4. Cho JH, Citardi MJ, Lee WT, et al. Comparison of Frontal Pneumatization Patterns between Koreans and Caucasians. Otolaryngol Head Neck Surg. 2006;135(5):780-786.

5. Lee WT, Kuhn FA, Citardi MJ. 3D Computed Tomographic analysis of Frontal Recess Anatomy in Patients without Frontal Sinusitis. Otolaryngol Head Neck Surg. 2004;131(3):164-173.

6. Angelico F, Rapaoport P. Analysis of the Agger Nasi Cell and Frontal Sinus Ostium Sizes using CT of the Paranasal Sinuses. Braz J Otorhinolaryngol. 2013;79(3):285-292.

7. Keast A, Yelavich S, Dawes P, et al. Anatomical Variations of Paranasal Sinuses in Polynesian and New Zealand European Computerized Scans. Otolaryngol Head Neck Surg. 2008;139(2):216-221.

8. Nouraei SA, Elisay AR, Dimarco A, et al. Variations in Paranasal Sinus Anatomy: Implications for the Pathophysiology of Chronic Rhinosinusitis and Safety of Endoscopic Sinus Surgery. J Otolaryngol Head Neck Surg. 2009;38(1):32-37.

9. Kennedy DW, Bolger, WE Zinreich SJ. Disease of the Sinuses, Diagnosis and Management, B.C. Decker Inc. Hamitton. London. 2001.

10. Reddy UD, Dev B. Pictorial Essay: Anatomical variations of paranasal sinuses on multidetector computed tomography-How does it help FESS surgeons? Indian J Radiol Imaging. 2012;22(4):317-324.

11. Ahmet Kaygusuz, Mehmet Haksever, Davut Akduman, et al. Sinonasal Anatomical Variations: Their Relationship with Chronic Rhinosinusitis an Effect on the Severity of Disease-A Computerized Tomography Assisted Anatomical Clinical Study. Indian J Otolaryngol Head Neck Surg. 2014;66(3):260-266.
12. Michael Stewart, BJ Ferguson, Len Fromer. Epidemiology and Burden of Nasal Congestion. Int J Gen Med. 2010;3:37-45.

13. Harnsberger HR. Diagnostic Imaging: Head and Neck. Canada: Amirsys Publishing, Inc. 2011

14. Santos, Christopher, Jarin, et al. Computed Tomographic Analysis of Paranasal Sinus Anatomic Variations among Filipinos. The Philippine Journal of Otolaryngology Head and Neck Surgery. 2003;19(3-4):155160 .

15. Seyyed Abdollah Madani, Seyyed Abbas Hashemi, Amir Hosein Kianejad, et al. Association between Anatomical Variations of the Sinonasal Region and Chronic Rhinosinusitis: A Prospective Case Series Study. Acta Facultatis Medicae Naissensis. 2013;30(2):72-77.

16. Avila PC. Epidemiology of Chronic Rhinosinusitis. In: C. A. Akdis, Global Atlas of Allergic Rhinitis and Chronic Rhinosinusitis. European Academy of Allergy and Clinical Immunology. 2015;307-308.

17. Brazilian Guidelines on Rhinosinusitis. Brazilian Journal of Otorhinolaryngology. 2008;74(2):6-49.

18. Jiann Jy Chen, Dem Lion Chen, Chi Jen Chen. The Lund-Mackay Score for Adult Head and Neck Computed Tomography. Chinese Journal of Radiology. 2011;36(4):203-208

19. Kountakis S, Onerci T. Rhinologic and Sleep Apnea Surgical Techniques. Heidelberg: Springer-Verlag Berlin. 2007.

20. Harnsberger HR. Handbook of Head and Neck Imaging (2nd ed.). St. Louis, Missouri: Mosby-Year Book, Inc.

21. Shpilberg KA, Daniel SC, Doshi AH, et al. CT of Anatomic Variants of the Paranasal Sinuses and Nasal Cavity: Poor Correlation with Radiologically Significant Rhisnosinusitis but Importance in Surgical Planning. AJR Am J Roentgenol. 2015;204(6):1255-1260. 